\title{
Developing Benchmarks For Prior Learning Assessment: An Exploratory Study
}

Malcolm Day, RN, University of Nottingham, UK

\begin{abstract}
Prior Learning Assessment (or PLA) has assumed a new importance for Nurse Education in the $U K$ as the Nursing and Midwifery Council has recently indicated that up to 50\% of the pre registration nursing programme could be achieved by an individual -through an assessment of their prior learning. [1]. However, despite the emergence of PLA guidelines for higher education institutions [2], the assessment of prior learning in UK universities is still: "Characterized by inconsistency and lack of coherence." [3] .This paper discusses the results of an exploratory study, which attempted to make the practice of PLA in UK Schools of Nursing clearer and much more explicit. A benchmarking approach is used, based on original work conducted within North America [4]. The findings show that benchmarks for PLA can identify the key purpose; functions and activities associated with the PLA Adviser and PLA Assessor role. Also, contrary to the literature PLA methodology is not based on any particular ideology. Rather, it appears to be context dependent and is more likely to be influenced by: (a) the needs of the individual; (b) the time and resources that are available; and (c) university regulations. This finding suggests that a more eclectic approach towards PLA might now be emerging within UK Schools of Nursing. Each of these findings is now the subject of further study.
\end{abstract}

Keywords: Prior Learning Assessment; PLA; PLA Advisor; PLA Assessor; Benchmarking; Nurse Education

\section{WHAT IS PRIOR LEARNING ASSESSMENT?}

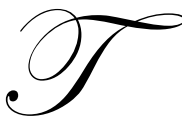

he term Prior Learning Assessment (PLA) includes Assessment of Prior Learning (APL).It also includes APCL or Accreditation of Prior Certificated Learning i.e. learning for which certification has already been awarded. The term also includes Accreditation of Prior Experiential Learning (APEL) which refers to un-certificated learning gained through experience. In Canada, the term PLAR or Prior Learning Assessment and Recognition is used. The term Recognition of Prior Learning (RPL) is used in South Africa. For example, Motaung [5] states that the purpose of RPL is to: “... address issues of social justice... increase the participation rate of historically disadvantaged groups ... and to improve the knowledge and skills base of the workforce in pursuit of global competitiveness."

The Canadian Association for Prior Learning or CAPLA [4] states that PLA is a systematic process that involves the identification, documentation, assessment and recognition of learning. This learning may be acquired through formal and informal study including work and life experience, training, independent study, volunteer work, travel, and hobbies and family experiences. This learning can be used towards the requirements of education and training programmes, occupational and/or professional certification.

Challis [6] states that the process of PLA includes: (1) the identification of learning, wherever it has taken place; (2) the selection of that learning that is relevant to an outcome, career or occupation; (3) demonstration of the validity and appropriateness of the learning; matching learning outcomes to those within a chosen accreditation framework; (4) assessment of evidence against criteria to ensure validity of the claimed learning; and (5) accreditation within a recognised accreditation framework .

Prior Learning Assessment has assumed a new importance for Nurse Education in the UK as the Nursing and Midwifery Council has indicated that up to $50 \%$ of the pre registration nursing programme can be achieved by assessment of the learner's prior learning [1]. 
Butterworth [7] indicates that two contrasting models for PLA have emerged since the 1970s. Firstly, the credit exchange model. The learner identifies areas of a program they have achieved, and then offers evidence of these past achievements. Credit is awarded if the assessor and verifier agree that the evidence shows the necessary competence. Secondly, the developmental model, which emphasizes the use of documentary evidence supported by reflective commentary. The learner's reflection is supported by discussions with a tutor. The purpose of these discussions is to support the learner's personal and professional development. The assessor judges both the evidence and the reflective personal account within the portfolio before recommending that appropriate credit is awarded.

Trowler [8] states that the credit exchange approach is derived from a behavioural model of learning and has no place in higher-level learning. Butterworth [7] explains that the developmental approach is based on a legitimate pedagogy for higher education as it assists the learner to undertake an analysis of their own practice and to increase their professional expertise.

This view is supported by Andersson [9] who states the purpose of the developmental approach is to: “... inform and change the continuing learning process." It is also supported by Popova-Gonci [10] who in proposing building blocks for PLA communities in the USA states that we should: “...celebrate PLA as a learning process..."

Further, a study conducted by Swegers et.al. [11] identified two types of PLA portfolio the recognition portfolio and the acknowledgement portfolio. The recognition portfolio mainly fulfils a formative function, while the function of the acknowledgement portfolio is primarily summative. However, Swegers et.al [11] argued that the processes involved in building either type of portfolio are not mutually exclusive. This is interesting, as their work suggests that a more integrated approach to PLA is now emerging.

\section{What is Benchmarking?}

Organizations can use benchmarking to solve problems, plan and set goals, and improve processes. By using a number of well-defined and easily understood indicators, weak spots in internal processes can be identified and compared to the most effective operating systems or best practices in leading organizations. (APQC [12], Patterson, [13]). In this study, the work of UK PLA practitioners is benchmarked against the work of Canadian PLA practitioners who have developed international benchmarks for prior learning assessment (CAPLA, [4]).

\section{The Research Problem}

Successive Government policies for Higher Education have indicated an intention to increase participation rates by developing the credit based systems already in operation within Higher Education Institutions (DES [14]) and in 2004 the Quality Assurance agency for Higher Education developed PLA guidelines for UK Higher Education Institutions [3]. However, a study by NIACE in 2008 reported that PLA in Higher Education was still: "Characterized by inconsistency and lack of coherence." (NIACE [3]).

The literature suggests that the practice of PLA has not been developed, or refined, through a process of systematic enquiry (Trowler, [8]). Rather, it has been based upon: "happenstance, coincidences and flukes of timing." Evans [15]. Consequently, there appears to be a dearth of systematic research based literature relating to the practice of PLA in Higher Education. However, a brief review of espoused theory has revealed significant tensions underpinning the work of PLA practitioners within UK higher education institutions. These are categorised in Table One (below) and have been used to develop an investigative framework for this exploratory study.

Table One: The Tensions Underlying PLA Practice in Higher Education.

Objectivity versus Bias i.e. academics have higher expectations of PLA students than those who are attending taught courses, and are therefore biased in the way they assess non-institutional learning For example see Merrifield et.al [16]

Equality versus Elitism i.e. Professions are now considering alternative forms of entry for individuals with vocational qualifications. There is a concern that this may lead to a drop in standards. For example, see: Peruniak and Powell [17] 
Internalization versus Alienation of learning i.e. there is a belief that PLA activity may become so focussed on meeting assessment outcomes that learners become alienated from the learning they have experienced. For example see: Popova-Gonci [10]

Quality versus Excessive surveillance i.e. the need to quality assure assessment outcomes must be balanced against the purpose of the assessment, as well as the desire for utility (Andersson, [9]).

Congruence versus Discord i.e. if academics cannot agree that PLA is a systematic and rigorous form of assessment (congruence) perhaps it is not surprising that students also have difficulty in understanding the process, and often have unrealistic expectations of PLA (discord).

The tensions outlined in Table One (above) appear to focus on the relative merits of either a credit exchange (Product) or a developmental model of PLA (Process). However, it is the author's belief that PLA is being practiced in a less divergent way in UK Schools of Nursing and that practitioners have become quite pragmatic in order to resolve the tension and discord that has previously underpinned their practice. This study challenges these assumptions by taking a developmental and collaborative approach towards the establishment of agreed benchmarks for PLA practice, which can lend clarity to the role and performance of practitioners and the assessment process they may follow. Therefore, this study asks the following research question: "Can benchmarks for PLA practice in UK Schools of Nursing be agreed?"

\section{The Sample}

Kennedy [18] has found that a lack of sustained funding, and unclear institutional policies, may significantly influence the practice of PLA. Therefore, if a clear and accurate picture of PLA activity is to be achieved it is important to determine whether practitioners : (1) are supported by regular and sustained funding; (2) work within established policy and procedure for PLA; and (3) process significant numbers of PLA candidates. With this point in mind an initial screening survey was sent to Heads of Schools of Nursing in England, Northern Ireland, Scotland and Wales $(\mathrm{n}=66)$. The returns from this survey identified a sample of 22 practitioners who: (1) actively processed PLA candidates, (2) were supported by continued funding for PLA work; (3) worked within established policy and procedure for PLA. This cohort was identified as "Expert" practitioners for the study. Those who did not meet the inclusion criteria were included as "Novices " $(\mathrm{N}=12)$. The total number of participants $(\mathrm{N}=34)$ was limited by application of the inclusion criteria adopted for the study (Kennedy[19]). However, it was later found that there was no significant difference between the responses from experts and the responses from novices suggesting (perhaps) that a larger sample could be drawn from the field if this study was to be replicated. However, given the exploratory nature of this study it was felt that this relatively small number was justifiable at this stage.

\section{Ethical Issues}

The APQC [12] stress the need for bench markers to be aware of the culture and context in which they are working, so that an appropriately sensitive approach towards bench marking can be undertaken. Although none of the participating institutions required a submission to individual research ethics committees. It was felt necessary to pay attention to: (1) the informed consent of participants; (2) the right of participants to "opt out" of the study; and (3) non -disclosure of information to third parties. For example, some responses in this study are reported anonymously.

\section{The Benchmarking Survey}

The benchmarking survey was based on the questionnaire developed for the National Canadian PLA Bench marking study (CAPLA [4]). This was tested for face validity and content validity with 17 practitioners who were a mix of expert and novices. Each was asked to comment on the structure of the benchmarks, and the time it took to complete the questionnaire. Those who were consulted felt that the questionnaire items were generally representative of PLA functions in the UK. For example, one practitioner stated: "As far as I can see the questionnaire covers the objectives, activities and issues involved in being a PLA Assessor." Feedback also indicated that the PLA Adviser and the PLA Assessor roles (which were separate and quite distinct) were similar to 
those practiced within UK faculty. With regard to the clarity, structure and time taken to complete the questionnaire, no difficulty was reported with language or timing e.g. it took one respondent only 15 minutes to complete all of the questionnaire items.

All of the items from the original Canadian survey were retained and included in the main UK survey, which was administered to Experts $(n=22)$ and Novices $(n=12)$. Each was asked to consider whether the benchmarks accurately described their current practice. They were asked to indicate "Yes," (it did), "No," (it did not), or if they were "Not Sure." Respondents were asked to justify their response by adding r comments and to make relevant changes to the language used in the benchmarks. Twenty-one questionnaires were returned by the stated deadline, an overall response rate of $61 \%$. Thirteen questionnaires were returned by Experts. Eight questionnaires were returned by Novices. One novice indicated that he/she was not involved in nursing education his/her response was discarded. Five experts (23\%) left the study before they completed the questionnaire. Three left because of pressure of work. Two left due to changes in role. All non- respondents were contacted by E-mail and asked to give a reason for not returning the questionnaire. The following reasons were given (1) pressure of work; (2) changes in role; and (3) concern about their own expertise.

\section{Results}

The responses to the benchmarked items are presented in Tables Two to Ten. These show that, with the exception of Table Two (below) both Experts and Novices agreed that the functions and activities contained within the bench marked items were an accurate description of their role.

Table Two: Function 2 -Assess The Individual. Activity I - Agree to and Review an Assessment Plan

\begin{tabular}{|l|c|c|c|c|}
\hline \multicolumn{1}{|c|}{ Cohort } & Yes & No & Unsure & N \\
\hline Experts & $54 \% 7$ & $7 \% 1$ & $38 \% 5$ & 13 \\
\hline Novices & $27 \% 3$ & $12 \% 1$ & $50 \% 4$ & 8 \\
\hline
\end{tabular}

With regard to Table Two, there was significant disagreement between Experts (Yes= 54\%), and Novices (No $=27 \%$ ). Also, experts $(45 \%)$ and novices $(62 \%)$ were unable to determine whether the above activity was an accurate description of their role. This difference of opinion can be explained by the following comment: "I would not write a plan for assessment to share with the applicant." Also: "This is a verbal agreement." Although an assessment plan may not exist in writing, or may not be copied to the student, this does not detract from the principle that an action plan is agreed. The wording of the emergent benchmarks was changed to reflect this finding (Table Eleven).

The Results of the bivariate analysis for the remaining items are now presented (Tables Three to Ten).

Table Three: The Key Purpose Of A PLA Assessor

\begin{tabular}{|l|c|c|c|c|}
\hline \multicolumn{1}{|c|}{ Cohort } & Yes & No & Unsure & N \\
\hline Experts & $\mathbf{9 2 \% 1 2}$ & $0 \%$ & $7 \% 1$ & 13 \\
\hline Novices & $\mathbf{6 2 \%} \mathbf{5}$ & $25 \% 2$ & $12 \% 1$ & 8 \\
\hline
\end{tabular}

The majority of experts $(92 \%)$ agreed this was an accurate description of their practice. This result has a high degree of validity as this group met the inclusion criteria adopted for the study, and could therefore be regarded as experienced practitioners.

Table Four: Function 1 - Prepare The Individual For Assessment.

This may include the following activities: help the individual to identify relevant learning; agree to and review an action plan for demonstration of prior learning; and help the individual to prepare and present evidence for assessment.

\begin{tabular}{|l|c|c|c|c|}
\hline \multicolumn{1}{|c|}{ Cohort } & Yes & No & Unsure & N \\
\hline Experts & $\mathbf{9 2 \% 1 2}$ & $7 \% 1$ & $0 \%$ & 13 \\
\hline Novices & $\mathbf{8 7 \%} \mathbf{7}$ & $12 \% 1$ & $0 \%$ & 8 \\
\hline
\end{tabular}

Both experts (92\%) and Novices (87\%) agreed that these activities were an accurate description of their practice. 
Table Five: Function 2 - Assess The Individual.

This may include the following activities: agree to and review an assessment plan; judge evidence and provide feedback; and make an assessment decision using differing sources of evidence and provide feedback.

\begin{tabular}{|l|c|c|c|c|}
\hline \multicolumn{1}{|c|}{ Cohort } & Yes & No & Unsure & N \\
\hline Experts & $\mathbf{7 6 \% ( 1 0 )}$ & $7 \%(1)$ & $15 \%(2)$ & 13 \\
\hline Novices & $\mathbf{8 7 \%}(\mathbf{7})$ & $12 \%(1)$ & $0 \%$ & 8 \\
\hline
\end{tabular}

Both experts $(76 \%)$ and Novices $(87 \%)$ agreed that these activities were an accurate description of their practice. Twenty-two per cent of Experts were unclear $(\mathrm{No}=7 \%$, Unsure $=15 \%)$. This diversity of opinion can be explained by the following comment: "I carry out formative assessment, but I do not undertake the final summative assessment that leads to accreditation." It appears (in this case) that summative assessments are undertaken by faculty board.

Table Six: Function 1 - Prepare The Individual For Assessment. Activity 1 - Help the individual to identify relevant learning.

\begin{tabular}{|l|c|c|c|c|}
\hline \multicolumn{1}{|c|}{ Cohort } & Yes & No & Unsure & N \\
\hline Experts & $\mathbf{8 4 \% ( 1 1 )}$ & $0 \%$ & $15 \%(2)$ & 13 \\
\hline Novices & $\mathbf{1 0 0 \% ( 8 )}$ & $0 \%$ & $0 \%$ & 8 \\
\hline
\end{tabular}

Eighty-four per cent of Experts, and $100 \%$ of Novices agreed that the above activity accurately reflected their role. Fifteen per cent of Experts were unsure. This can be explained by the following comment: "The bench marking statement suggests a long leisurely approach. Our candidates only find out a few weeks before the commencement of a course that they are attending, therefore our schema is often time limited. "It would appear that this practitioner had a more streamlined view of the PLA process, which is time sensitive, and dependent upon number of candidates to be processed.

Table Seven: Function 1 - Prepare The Individual For Assessment. Activity II Agree to and Review an Action Plan

\begin{tabular}{|l|c|c|c|c|}
\hline \multicolumn{1}{|c|}{ Cohort } & Yes & No & Unsure & N \\
\hline Experts & $\mathbf{8 4 \% ( 1 1 )}$ & $7 \%(1)$ & $7 \%(1)$ & 13 \\
\hline Novices & $\mathbf{1 0 0 \% ( 8 )}$ & $0 \%$ & $0 \%$ & 8 \\
\hline
\end{tabular}

Eighty-four per cent of Experts and $100 \%$ of Novices agreed that the above activity accurately reflected their role. Fourteen per cent of Experts were unclear $(7 \%=$ No, $7 \%=$ Unsure). This can be explained by the following comment: "This is a verbal agreement with written records being kept by myself." Some practitioners use more informal approaches towards action planning.

Table Eight: Function 1 - Prepare The Individual For Assessment. Activity III Help the Individual to Prepare and Present Evidence for Assessment

\begin{tabular}{|l|c|c|c|c|}
\hline \multicolumn{1}{|c|}{ Cohort } & Yes & No & Unsure & N \\
\hline Experts & $\mathbf{8 4 \% ( 1 1 )}$ & $7 \%(1)$ & $7 \%(1)$ & 13 \\
\hline Novices & $\mathbf{8 8 \% ( 7 )}$ & $0 \%$ & $12 \%(1)$ & 8 \\
\hline
\end{tabular}

The results relating to this item are clear. The majority of Experts and Novices agreed that the above activity accurately reflected their role.

Table Nine: Function 2 - Assess The Individual. Activity II - Judge Evidence and Provide Feedback.

\begin{tabular}{|l|c|c|c|c|}
\hline \multicolumn{1}{|c|}{ Cohort } & Yes & No & Unsure & N \\
\hline Experts & $\mathbf{8 4 \% ( 1 1 )}$ & $0 \%$ & $15 \%(2)$ & 13 \\
\hline Novices & $\mathbf{8 7 \% ( 7 )}$ & $12 \%(1)$ & $0 \%$ & 8 \\
\hline
\end{tabular}


Although $84 \%$ per cent of Experts agreed with this statement, $15 \%$ were unsure. This can be explained by the following comment: "Our APL scheme only caters for practitioners who want access with credit for other programmes. We do not give a general credit rating for professional development." The majority of experts take a developmental approach when giving feedback. However, there are a minority of practitioners who do not see this as part of the PLA process. Although $12 \%$ of Novices disagree with this statement, this finding should be interpreted with caution as Novices do not meet the inclusion criteria for the study and therefore have limited experience of PLA.

Table Ten: Function 2 - Assess The Individual. Activity III Make an Assessment Decision Using Differing Sources of Evidence and Provide Feedback

\begin{tabular}{|l|c|c|c|c|}
\hline \multicolumn{1}{|c|}{ Cohort } & Yes & No & Unsure & N \\
\hline Experts & $\mathbf{8 4 \% ( 1 1 )}$ & $0 \%$ & $15 \%(2)$ & 13 \\
\hline Novices & $\mathbf{8 7 \% ( 7 )}$ & $12 \%(1)$ & $0 \%$ & 8 \\
\hline
\end{tabular}

Eighty-four per cent of Experts agreed with this statement. However, 15\% were unsure this uncertainty can be explained by the following comment: "The evidence required will depend on the size of the credit claimed, the level, the course against which the claim is made and the claim itself- whether APCL or APEL or both combined. Thus each situation has to be prepared and evidence individually."Although this individual recognised the complexity and diversity of PLA practice, it appeared that he or she was reluctant to commit his or her view to paper. It may well be that he or she had some philosophical concerns regarding the potential use of PLA benchmarks

\section{Changes to Language}

Respondents were invited to make changes to any of the wording contained within the bench marked items. Only 2 respondents did this. With regard to the key purpose of the PLA practitioner: one respondent confirmed that academic credit and professional certification was: "currently our main purpose." With regard to the language used to describe an assessment outcome: one respondent confirmed that: "Outcomes are those of the module against which the claim is being made." As a consequence the phrase: "agreed - upon criteria" was deleted and replaced with the term "outcomes" With regard to the use of formal versus informal action planning: one respondent indicated: "There is no actual action plan. There is a discussion. This happens verbally." This view was supported by other respondents, who were concerned about time and resource implications for undertaking this type of activity. The newly emergent benchmarks were modified to reflect this finding. Finally, with regard to the emphasis on formative as well as summative assessment: one respondent made the following general comment: "No assessment is purely summative. How do we keep the formative alive?" This comment appears to support the interest that practitioners had in using developmental as well as credit based approaches towards PLA. The newly emergent benchmarks were modified to include this finding by providing a definition of the terms: Formative and: Summative. (see: Table Eleven below). The newly emerging benchmarks are outlined in Table Eleven. Changes to language are in bold. For brevity, the elements for each functional activity have not been included - these can be obtained from the author.

Table Eleven: Newly Emerging Benchmarks for PLA Practice

\section{Key Purpose}

The key purpose of the PLA Practitioner in UK Schools of Nursing and Midwifery is to: Review progress and/or assess achievements; so that individuals and organisations can achieve their personal development and/or education and training objectives. This includes assessment of individuals for academic credit and professional certification. The main functions and activities of the PLA Practitioner's role are to:

Function 1 - Prepare The Individual For Assessment: This includes the following activities:

(I) help the individual to identify relevant learning outcomes

(II) agree to and review an action plan for demonstration of prior learning. The action plan may be a verbal or written agreement between the PLA practitioner and the learner. It may also take the form of a learning contract.

(III) help the individual to prepare and present evidence for assessment. 
Function 2 -Assess The Individual. This includes the following activities: This may include the following activities:

(I) Progress formative assessment activities and judge evidence and provide feedback. Formative assessments are designed to provide learners with feedback on progress and inform development, but do not contribute towards the overall assessment.

(II) Contribute to making a summative assessment decision using differing sources of evidence and provide appropriate feedback. Summative assessments provide a measure of achievement or failure made in respect of a learner's performance in relation to the intended learning outcomes of a programme of study.

(III) Contribute to making a summative assessment decision using differing sources of evidence and provide appropriate feedback.

NB. PLA Practitioners in UK Schools of Nursing may carry out both of these functions.

\section{Comments from Respondents}

Respondents were asked to justify their responses by writing a commentary. Most of the commentraries received appeared to view PLA from two distinct and differing standpoints. That is: (1) PLA as a Product; or (2) PLA as a Process. For example, one expert indicated:

"... the main type of claim with which I deal tends to be Accreditation of Prior Certificated Learning (APCL)." While one expert stated: "The student develops an extended CV identifies prior learning and writes reflection pieces and gathers evidence of learning."

However, contrary to the above findings some practitioners indicated that they used both product and process. For example, one expert stated:

"Any assessment is made on diverse sources of evidence. The evidence required will depend on the size of the credit claimed, the level, the course against which the claim is made and the claim itself- whether APCL or APEL or both combined."

This finding seems to indicate the existence of a continuum for PLA practice - where both product and process approaches are used in a combined way to meet the individual needs of the learner, and to assess the outcomes of their learning. This finding is supported by previous research undertaken by the ENB [19] who indicated that: "A model of $A P(E) L$ is in use which appears to be halfway between APL and APEL.."

Other comments centred around the factors that most influenced PLA practice these included: (1) the individual needs of the learner; (2) the time and resources available to the practitioner; and (3) university regulations.

All of the above comments were categorised (Table Twelve) and are now the subject of further qualitative analysis.

Table Twelve: Factors Influencing PLA Practice: A Schema for Further Qualitative Analysis

\begin{tabular}{lllll}
\hline$C$ & & & & $\mathrm{C}$ \\
$O$ & Time and Resources & & PRODUCT & $\mathrm{O}$ \\
$N$ & & & $\boldsymbol{\uparrow}$ & $\mathrm{N}$ \\
$T$ & University Regulations & $\Rightarrow$ & $\boldsymbol{\uparrow}$ & $\mathrm{T}$ \\
$E$ & & & $\boldsymbol{N}$ & $\mathrm{N}$ \\
$X$ & Individual Learning Needs & $\Rightarrow$ & PROCESS & $\mathrm{U}$ \\
$T$ & & & $\mathrm{M}$ \\
\hline
\end{tabular}




\section{CONCLUSION}

An analysis of quantitative data emerging from a survey of PLA practice has confirmed that both PLA Experts and Novices can agree with the overall functions and activities contained within the bench marked items. This is contrary to what was expected as it was first thought that Expert and Novice practitioners could have a different perception of the PLA practitioner's role. This finding is important as it will allow the researcher to wave the inclusion criteria that were originally applied and (potentially) enable a larger sample to be identified for a further survey. In addition, qualitative data emerging from respondent's commentaries indicates that practitioners utilise either a product $\underline{\text { or }}$ a process based approach towards PLA. Also, there is evidence to show that some practitioners utilise both product and process based approaches towards PLA. This finding suggests that a continuum for PLA practice might be in existence. That is, practitioners probably combine both product and process methodologies in order to meet the individual needs of the learner. This finding is consistent with the previous work of Johnson [20] who stated that an "all-through" or holistic model of PLA was in existence. It is also consistent with the experience of the Flemish practitioners Swegerset.al [11] who have since found that the processes involved in developing "recognition" or "acknowledgement " portfolios are not necessarily mutually exclusive. Finally, in this exploratory study it appears that assessment methodology is not based on ideology but is context dependent and is more likely to be influenced by: (1) the needs of the individual; (2) the time and resources that are available; and (3) university regulations. This finding supports the researcher's assumption that a more eclectic approach towards PLA is emerging within UK Schools of Nursing. These findings are now the subject of further investigation.

\section{AUTHOR INFORMATION}

Malcolm Day RN. B.Ed. M. Ed. M.Phil. FIfL. FHEA. is a Lecturer in Adult Nursing and PLA Advisor in the School of Nursing at Nottingham University, England. He is also an advisor to the Centre for Indigenous and Holistic Learning and PLA, First Nations Technical Institute, Tyendinaga Mowhawk Territory, Ontario, Canada. E-mail: Malcolm.day@nottingham.ac.uk

\section{REFERENCES}

1. Long, G. 2010. NMC requirements, guidance and advice for accreditation of prior experiential learning (APEL) in new pre-registration nursing programmes. APEL Guidance 050710. Nursing and Midwifery Council, London,

2. QAA 2004. Guidelines for the Accreditation of Prior Learning. QAA 064 09/04. Quality Assurance Agency for Higher Education, Gloucester.

3. NIACE. 2008. Accreditation and Recognition of Prior Experience and Learning JISC Funded Project, July 2008. NIACE, Leicester.

4. CAPLA. 2000. Developing Benchmarks for Prior Learning Assessment. Canadian Association for Prior Learning Assessment. Peace Tree printing. Ontario.

5. Motaung, J. 2009. The 'nuts and bolts' of prior learning assessment in the Faculty of Education of the University of Pretoria, South Africa. Perspectives in Education, 27(1), 78-84

6. Challis, M. 1993. Introducing APEL. Routledge, London.

7. Butterworth, C.1992. More than one bite at the APEL: contrasting models of accrediting prior learning. Journal of Further and Higher Education. 16 (3) 39-51.

8. Trowler, P. 1996. Angels in marble? accrediting prior experiential learning in higher education. Studies in Higher Education. 21 (1).17-30.

9. Andersson, P, 2006. Different faces and functions of RPL: an assessment perspective. Chapter 2, IN: Andersson, P; and Harris, J. Re-theorising the Recognition of Prior Learning. NIACE, Leicester. ISBN 1 862012652

10. Popova-Gonci, V. 2009. 'All Work and No PLA Makes Jack a Dull Boy', The Journal of Continuing Higher Education, 57: (1) $42-44$

11. Sweygers, Annelies, Soetewey, Kim, Meeus, Wil, Struyf, Elke and Pieters, Bert. 2009. 'Portfolios for Prior Learning Assessment: Caught Between Diversity and Standardization', The Journal of Continuing Higher Education, 57: (2), 92 - 103 
12. American Productivity and Quality Center. 1997. Bench marking: Pure and Simple. APQC, Texas.

13. Patterson, J.G. 1996. Benchmarking Basics. Crisp Publications, California.

14. Department for Education and Skills. 2003. The Future of Higher Education. Creating Opportunity, Releasing Potential, Achieving Excellence. White Paper. CMM 5735

15. Evans, N. 2000. The Evolution of AP(E)L in England. IN: Evans, N. (Ed). Experiential Learning Around the World: Employability and the Global Economy. Jessica Kingsley, London. ISBN 1853027367

16. Merrifield, J. et. al. 2000. Mapping APEL: Accreditation of Prior Experiential Learning in English Higher Education. Learning from Experience Trust. Goldsmiths College, London.

17. Peruniak, G and Powell, R 2007. Back Eddies of Learning In the Recognition of Prior Learning. Canadian Journal of University Continuing Education Vol. 33, No. 1, Spring 2007 pp. 83-106

18. Kennedy, B. 2003. A Spring 2003 Snapshot. The Current Status of Prior Learning Assessment and Recognition (PLAR) in Canada's Post Secondary Institutions. Canadian Association for Prior Learning Assessment.

19. ENB .1997. An investigation into the reliability and validity of assessment strategies for the accreditation of prior learning of nurses, midwives and health visitors. Research Highlights, No.26. English National Board, for Nursing, Midwifery, and Health Visiting. London.

20. Johnson, B. 2002. Models of APEL and Quality Assurance. Southern England Consortium for Credit Accumulation and Transfer, SEEC. Cravitz Printing Co. Ltd, Brentwood, Essex. ISBN 0-9541375-0-7. 
NOTES 